\title{
CRISE NEO-LIBERAL E ALTERNATIVA SOCIALISTA
}

José Valenzuela Feijóor

(tradução: Antônio Gomes da Silvaª)

"Quem quer / que o mundo /

siga sendo/comó /

nĩo quer / que siga sendo".

Eric Fried

\section{INTRODUÇ̃̃o}

Nas últimas duas décadas, o modelo neo-liberal se estendeu a vários países latino-americanos. Em termos de acumulação e crescimento, seu desempenho tem resultado mais que medíocre. Em termos de distribuição de vencimentos, o balanço é talvez pior. Por isto mesmo, não se deve estranhar que comece a surgir o descrédito do modelo.

Por certo, para os muito minoritários grupos sociais impulsores do padrão neo-liberal, os benefícios têm sido imensos e, por isto mesmo, não cabe esperar que renunciem a sua defesa. Como, no entanto, o esquema é incapaz de dinamizar a acumulação e o crescimento, esse interesse particular näo poderá transformar-se em interesse geral. Quer dizer, ao não ser capaz de encarnar a necessidade histórica do capital no atual momento do decurso latino-americano, suas

1 Professor da UNAM - Universidad Antónoma Metropolitana - Unidad Iztapalapa.

${ }^{2}$ Mestre en Irilosofia. Prof. do Depto. de Sociologia e Antropologia/UFPB - Campus II. 
possibilidades de consolidação efetiva e de longo prazo são praticamente nulas.

Neste contexto, torma-se mais premente a pergunta por estratégias alternativas à estratégia neo-liberal.

As possíveis rotas alternativas se podem diferenciar de acordo com o seu conteúdo sócio-político. Neste scntido, poderíamos distinguir: a) estratégias de direita on antidemocráticas; b) rotas estratégicas mais progressistas e democráticas. (Quer dizer, que ao menos tomam en conta os interesses das grandes maiorias populares.

Quanto às primeiras, o padrão subjacente ć o denominado 'sccundário-exportador'. En sua versão neo-liberal, este padrão preserva os altos níveis de exploração e o regime político autoritário. Diferencia-se, no sentido de que opera com altas taxas de acmulaça. Isto, exatamente, pelo fato de ser a grande burguesia industrial monopolista (c nāo o capital financeiro) a que hegemoniza a conduçāo do projeto.

Quanto ao segundo tipo de estratégia, de corte mais esquerdista, se podem distinguir pelo menos duas grandes rotas possiveis: a) a 'capitalista democrática'; b) a de orientação 'socialista'.

A via do capitalismo democrático é cncabeçada pela burguesia industrial não monopolista. Supóe-se que o capitalismo democrático presta atençào aos interesses populares (trabalhadores e classes médias, camponeses), que trata de funcionar com uma distribuição de renda não muito regressiva (concentradora), que busca negociar a dependência em favor da nação e que estimula um regime político demo-burguês mais on menos avançado. Este padräo, visualizado do ponto de vista dos interesses do mundo do trabalho, possui limitaçoes maiores. Por seu conteúdo capitalista, năo pode climinar as relaçóes de exploração c a condiçáo subordinada do trabalho na muito decisiva esfera da produção. De modo análogo, no plano político não pode - por definição supcrar as limitantes que impóc à natureza mais essencial do Estado burguês e o tipo de atividade política que, nesse marco, podem exercer as massas trabalhadoras. Em breve, por mais demo- 
crático que possa ser, o capitalismo apresenta obstáculos insolúveis à plena autonomia e liberdade dos trabalhadores ${ }^{3}$.

Uma estratégia de orientação socialista é a que, com maior propriedade, pode satisfazer os interesses do mundo do trabalho e as grandes maiorias nacionais. Neste sentido, trata-se da estratégia alternativa que, nas condiçóes atuais, pode operar com um conteúdo democrático superior a que qualquer outra alternativa poderia oferecer, a seguir, discutircmos tanto a possibilidade quanto os conteúdos básicos desta estratégia.

Em primeiro lugar, trataremos de deslindar alguns conceitos e procedimentos básicos. Trata-se aqui, de evitar a usual confusão que hoje se faz entre o regine socialista e os regimes burocrático-autoritários, até há pouco imperantes na Europa Oriental. Logo, dado que o projeto socialista abarca um larguíssimo periodo histórico que cobre diversas fases, identificaremos àquela que se refere o grosso do desenho estratégico a propor. Finalmente, nesta seção, esboçaremos um esquema geral que permita ordenar a análise da mudança estrutural. Como neste trabalho abordaremos somente alguns aspectos da mudança proposta, ele nos permitirá posicionar tanto o que se discute, como o que, por razós de espaço, ficará na penumbra. Em segundo lugar, discutiremos brevemente as premissas que possibilitam ensaiar uma opçán socialista. En terceiro lugar, analisaremos as tarefas políticas centrais que devem satisfazer o projeto socialista. Estas têm que ver tanto com a organizaçăo estatal, como com o desenvolvimento de organismos civis intermediários. Em quarto lugar, discutiremos as tarefias economicas fundamentais a abordar no período. Finalmente, faremos uma breve menção das forças sociais em jogo, seu eventual alinhamento c os modos ou rotas pelas quais poderia transitar o projeto.

3 "Somos partidários da república democrática como al melhor forma do Estado para - proletariado no capitalismo; mas não temos o direito de olvidar que a escravidão assalariada co destino do povo, inclusive ma república burgtesa mais democrática". Cf. LENIN, V. I., El Esstado y la revolnción. In: Ob. Esc., Tomo 2. Moscou, Edit. Progreso, 1978. p. 30.5 . 


\section{Algumas CONSIDERAÇÕES PRELIMINARES}

1. MAL-ENTENDIDOS SOBRE O SOCIALISMO

$\mathrm{Na}$ atualidade, circulam toda classe de equívoco sobre o socialismo. Em quase todos eles, sucede identificar-se o socialismo com os regimes burocrático-autoritários vigentes na URSS e Europa Oriental, desde o imediato pós-guerra até aproximadamente meados dos anos oitenta. Estes regimes se derrubaram quase em uníssono e, em nível de opinião pública mundial, sua imagem é péssima. Por isso nesmo, a identificação destes regimes com o socialismo convém perfeitamente aos inimigos do socialismo. Para os amigos, tem sabor de rícino.

Para o caso, a pergunta ou teste chave deve apontar para a natureza do poder político nesses regimes. Eram os trabalhadores os que exerciam o controle do Estado e operavam, por conseguinte, como força social dominante? Un muito elementar repasse da realidade vigente nos países pertinentes - pense, por exemplo, na URSS dos tempos de Breshnev ou na China atual - basta para prevenir-se de que a classe trabalhadora está ou estava ali completamente privada do poder estatal. Quer dizer, funciona(va) como uma classe social dominada e explorada.

Não é menos certo que, nas origens destes regimes burocráticoautoritários, nos encontramos com projetos de orientação socialista, mais precisamente, temos projetos originalmente socialistas que, em pouco tempo, experimentam sérias dificuldades de implementação e começam a entrar em uma fase de degeneração burocrática. Na URSS, este período poderia estender-se desde 1917 até, aproximadamente, meados ou fins dos anos trinta. Logo, a fase degenerativa deste período daria lugar a uma mutação qualitativa maior, com transformaçōes na natureza da instituição estatal, da classe social dominante e mesmo do sistema econômico. En breve, emerge o regime que, à falta de outra denominação, chamamos burocrático-autoritário. Na URSS, este regime aparece já clara e perfeitamente consolidado no imediato pós-guerra ${ }^{4}$. A derrubada dos oitenta, portanto, não tem sido

${ }^{4}$ Uma análise mais cuidadosa poderia fixar o ponto de ruptura ainda anteriormente. Por exemplo, em torno dos tristemente famosos "julgamentos de Moscon", de 1937. En todo 
a derrubada do socialismo, senão dos regimes burocrático-autoritários. O socialismo, ainda que de existência muito embrionária, feneceu pelos anos trinta.

Para falar de socialismo, deveríamos encontrar duas condiçōes absolutamente indispensáveis: (i) um Estado de novo tipo, controlado por trabalhadores; (ii) um setor ou núcleo econômico socialista. Este deve entender-se como o conjunto de empresas nas quais os trabalhadores exercem o poder patrimonial e se apropriam do excedente. Quer dizer, o conjunto de empresas submetidas à propriedade do trabalho.

Para não poucos autores, o fracasso do socialismo e sua transformação em um regime burocrático-autoritário é um fenômeno inevitável e que demonstra, no melhor dos casos, que se trata de uma utopia incapaz de chegar a materializar-se na história ${ }^{5}$. Em suas origens, sobre o capitalismo se emitiam juízos bastante similares. Para os ideólogos do feudalisno - os clérigos em particular - o capitalismo era un atentado à natureza humana mesmo e, por isto, estava condenado ao fracasso. E que este, em países como Itália e Alemanha tivera sonoros fracassos, não fazia - em aparência - senão confirmar esses muito interessados prognósticos. Na realidade, se observarmos o problema com a suficiente perspectiva histórica, os fracassos não nos deveriam estranhar. Muito pelo contrário, os deveríamos considerar normais e previsíveis, próprios de uma fase de gênese.

\section{FASES NO DESENVOLVIMENTO DO PROJETO SOCIALISTA}

Se logra desenvolver-se à plenitude, o socialismo deveria abarcar um larguíssimo e complexo período histórico. Sua meta última e final é desaparecer como tal, algo que deveria ter lugar quando a sociedade estivesse en condiçôes de funcionar com os mais altos nî́veis

caso, neste ensajo não nos interessa tanto o exame concreto da história da URSS, senão a diferenciação entre o que podemos denominar "socialismo embrionário" e os regimes "burocrático-autoritários".

5 A pretensão é nuito clara: dár um certificado de disfunção per secula-seculorum ao projeto socialista. 
de produtividade, um completo grau de socialização das forças produtivas - o que possibilita e exige a sua gestáo unificada -, uma norma distributiva, em que cada qual trabalha segundo suas capacidades e se apropria segundo suas necessidades e em que o Estado e seus aparatos, por serem já desnecessários, tenhan deixado de existir.

Autes dessa fase, que sem dúvida não se encontra em qualquer esquina, poderíamos diferenciar um período de 'socialismo pleno'. Nele, o Estado deve responder às condiçóes já mencionadas e o sctor econômico socialista deveria abarcar o conjunto da economia.

Finalmente, poderíamos distinguir um periodo on ctapa de 'socialismo embrionário'. A natureza do Estado responde às condiçós já indicadas e o setor economico socialista é relativamente pequeno. Mais precisamente, coexiste com setores cuja natureza social é diferente: capitalista, de pequena produção mercantil, etc. Em breve, estaremos em presença de uma estrutura econômica beterogênea.

Em seu sentido mais anplo, o projeto socialista deve abarcaro vasto arco histórico que acabamos de insinuar.

Ademais, as fases inferiores cncontram toda sua siguificação somente à luz das metas últimas. Em um sentido mais estrito, podemos limitar o projeto ao que temos qualificado como 'socialismo embrionário'. Nos limites deste traballo, quando falamos de uma estratégia alternativa com orientação socialista, cstamos nos referindo a essa fasé inicial ou 'embrionária'.

\section{UM ESQUJPA DE ANÁLISE}

A caracterização de uma mudança estrutural como a que nos preocupa, se pode ordenar referindo-se a três aspectos ou dimensóes básicas: a) $\Lambda s$ atividades de transformação - quer dizer: que instituiçóes (relaçōes) sociais se pretende suprimir?, que instituiçóes (relaçóes) sociais se busca implementar e desenvolver?; b) $\Lambda$ s forças sociais em jogo, tanto as integrantes do bloco pela mudança como as que se alienam no bloco conservador; c) As viaș ou rotas que se supócm seguirão o processo de transformação. 


\subsection{As atividades}

Trata-se, aqui, de identificar a mudança social proposta e o lugar ou espaço (no sentido da formação economico-social) onde essa mudança se situa. Para o caso, poderia-se manejar um esquema ordenador como o que se expố a seguir.

Quabro: As Atividndes di: Mudanca SOCIAL - Qiunis e Onde

\begin{tabular}{|c|c|c|}
\hline 160000010 & 1011104 & 110010 \\
\hline $\begin{array}{l}\text { 1. Sistema de Forças Produtivas } \\
\text { l.l. Patrimônio (Acervos) }\end{array}$ & .... & .... \\
\hline 1.2. Produtividade & $\cdots$ & $\ldots$. \\
\hline 1.3. Estilos de Crescimento & .... & .... \\
\hline 2. Instituiçōes Ecomòmicas & & \\
\hline 2.1. Produçăo & $\therefore$. & $\cdots$ \\
\hline 2.2, Distribuiçäo & $\ldots$. & $\cdots$ \\
\hline 2.3. Trocas (Cil'culaçào) & .... & $\ldots$ \\
\hline 2.4. Consumo & $\cdots \cdot$ & $\cdots$ \\
\hline 3. Instituiçocs Políticas & & \\
\hline 3.1. Estado & $\cdots$ & ... \\
\hline 3.2. Outras & $\cdots$ & $\cdots$ \\
\hline 4. Instituiçōes Culturais & & \\
\hline 4.1. Educaçã̃o & .... & $\cdots \cdot$ \\
\hline 4.2 Outras . . & $\cdots$ & .... \\
\hline 5. Formas da Consciência Social & & \\
\hline 5.!. VaJores & $\cdots$ & $\cdots$ \\
\hline 5.2. Idéia do Mundo & $\cdots \cdot$ & ..." \\
\hline Outros & $\cdots$ & $\cdots \cdots$. \\
\hline
\end{tabular}

Por certo, os espaços se podem e devem trabalhar com una maior desagregação. E preencher os quadrinhos que dejxamos vazios, o das rclaçóes sociais a suprimir e o das relaçóes sociais a construir e desenvolver. Por exemplo, tratando-se de um projeto socialista, no espaço da economia, subestera da prodıção, haveria, ademais, que explicitar a regra das relaçóes de propriedade. $\mathrm{Na}$ lacuna que se pôe abaixo de "climinar" escrever relaçócs capitalistas monopolistas e abaixo de "implantar", relaçōes socialistas. O objetivo é ter um panorama de conjunto e analisar a coerência te articulação das mudanças propostas, seja em termos de 'suprimir' como em termos de 'construir'. 


\subsection{As forcas sociais em jogo}

O panorama das mudanças que a estratégia postula permite identificar as forças sociais prejudicadas e as forças sociais que se beneficiam com o modelo. Estas, devem contabilizar-se em termos de classes e/ou de fraçóes de classes.

Posto o anterior, pode-se proceder o esboço do que cabe denominar 'alinhamento potencial objetivo'. Primeiro, identificam-se todas as classes ou frações de classes, que ao se verem beneficiadas pelo modelo, podem, supostamente, tomar parte do 'bloco progressista'. Quer dizer, podem funcionar como forças impulsoras do novo esquema. No interior destas, por sua vez, deve-se identificar a que funciona como força dirigente e as que funcionam como forças aliadas ou bases sociais de apoio. Em segundo lugar, é preciso efetuar uma descrição análoga para o caso das classes e fraçōes de classe que, de acordo com seus interesses objetivos, devem formar o 'bloco conservador'. Quer dizer, trata-se de identificar as forças conservadoras.

$O$ anterior não necessariamente coincide com o 'alinhamento social eferivo'. Os fatores 'subjetivos' de talhe ideológico e político podem provocar alguma dissociação ou discrepância entre o "alinhamento potencial objetivo' e o efetivo. Em termos gerais, a discrepância pode funcionar em favor do bloco conservador. Por isto mesmo, para uma estratégia de orientação socialista, resulta vital reduzir em todo o possível essa discrepância. Quer dizer, maximizar a força social e política do bloco pela mudança.

Em algumas ocasiões, o alinhamento é muito tênue e quase não existe. Neste sentido, fala-se da possibilidade de uma neutralização de determinados estratos ou fraçōes. Quer dizer, se por um lado não se atrai essas forças para o bloco próprio, pelo menos evita-se que se integrem ativamente ao bloco inimigo. Para uma estratégia de talhe socialista, também pode resultar de grande importância aproveitar essa possibilidade.

\subsection{As vias ou modalidades de transformaçăo}

As modalidades que assumem o processo, obviamente, não são independentes do conteúdo da estratégia em jogo e do alinhamento 
de forças que precipita. Para nossos propósitos, nos pode bastar aludir a três aspectos ou dimensóes.

Primeiro, o que se refere à direção do processo: desde cima (istó é, desde as cúpulas do poder) até embaixo ou desde enbaixo até em cima. Esta segunda direção possível implica em uma grande mobilização popular e, certanente, é a que exige a implementação de uma estratégia socialista.

Segundo, a intensidade, extensão e duração da atividade política prévia. Em poucas palavras, tratam-se dos ímpetos que tipificam a fase de 'acumulaçāo de forças'. Estes ímpetos interessam enquanto influenciam decisivamente nas capacidades com que o mundo do trabalho assume o desafio socialista. Se a extensão é escassa (ou seja, se a luta prévia compromete uma pequena parte da população) e a duração muito breve, essas capacidades muito provavelmente deixarão muito a desejar.

Terceiro, o papel da violência armada e as modalidades que esta pode assumir. Como regra, nas condiçóes atuais, a possibilidade de una transição pacífica é mais que remota. E, se aceitamos esta suposição, surge a pergunta sobre a modalidade: via insurreicional urbana, guerra aberta e prolongada de corte rural, etc.

\section{AS PREMISSAS OU PRÉ-REQUISITOS MÍNIMOS}

O socialismo não é algo que possa implementar-se e funcionar a partir da pura vontade de certos grupos on agentes sociais. Para que possa chegar a modelar-se, necessitam-se de alguns requisitos ou condições mínimas que são produto do desenvolvimento histórico prévio. Para o caso, pode-se falar de premissas do socialismo e se elas não estão presentes, o projeto socialista, muito provavelmente, não poderá sequer ser ensaiado ou, por outro lado, no caso eventual de chegar a irromper, sua possibilidades de consolidação serão muito escassas. Insistamos: não se trata de uma impossibilidade absoluta, mas de condiçôes que, uma vez ausentes, tornam muito difícil o êxito ulterior do modelo.

Tratando de ser muito sintético, mencionaremos quatro premissas fundamentais. 
1. NivEl MINIMO DF DESHANOIVIMINTO B:CONOAMICO

Para o caso, poderíamos falar de um nível múnimo de produtividade do trabalho ou do produto por habitante. Mas, pode ser mais ilustrativo o uso de outros indicadores. Fm um sentido qualitativo, diriamos que é necessário que o capitalismo tenha se apoderado, basicamente, da agricultura. E, em função disto, exigir que a população ocupada na agricultura năo vá além de 12 a $15 \%$ da população economicamente atival total. Além disso, que o percentual de população rural năo supere mus 1.5 a $20 \%$ da população total.

Qual o raciocinio subjacente a este tipo de exigência?

Primeiro, trata-se de que a questão agrária tenha sido resolvida pelo desenvolvimento capitalista e não tenha que dela se encarregar o projeto socialista. Quer dizer, que não corresponda à revolução socialista executar as tarefas que a revoluçáo burguesa tenha deixado pendentes. Sob estas condiçóes, a aliança com os setores camponeses perde sua centralidade e, por si mesmo, desaparece ou se entraquece o ulterior problema de pedir às conomias camponesas niveis de produtividade que não estão $\mathrm{cm}$ condicoes de se obter'. Segundo, a partir de uma base agrária capitalista, os niveis e ritmos de crescimento da produtividade podem ser suficientemente altos para permitir um forte crescimento dos salários realis urbanos.

Terceiro, uma agricultura moderna está associada a uma população agrária permeável a agenda da racionalidade moderna e capaz. de assimilar tecnologias e modos de organização avançados. Quarto, o al to peso da população urbana pode assegurar o domínio de agendas culturais racional-abstratas e críticas. Estas, sendo indispensáveis a) funcionamento do capitalismo moderno (pelo menos em alguns dos seus aspectos, não em sua globalidade), o são ainda mais para o caso do socialismo.

"No caso da LRSS, esta exigência desembocou en uma estatizaçăo ou cooperativização forçala das economias camponesas. Com ela, a sitmação agrária terminou por piorar, alćm do que, rompeu-se a aliançi operário-canponesa e sc acentuaran os arroubos ditatoriais e burocráticos do listado sovictico. 


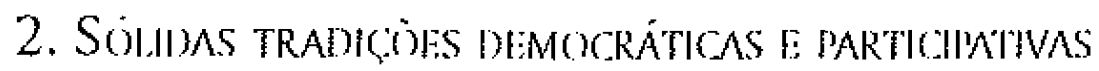

Trata-se, aqui, de que os trabalhadores - columa central do bloco progressista - tenhan se preocupado profundanente com a coisa pública e, muito especialmente, sua capacidade para assumir a organização e direção dos assuntos communs e públicos. Estas capacidades näo surgem de un dia para o outro. Por isto, sua presença supóc que houve lugar para un longo período prévio de desenvolvimento e aprofundamento das instituçóses e formas democráticas. Para o caso, a presença de una democracia burguesa plenai resulta de vital importância. Já Marx o dizia:

"O regime parbmentar vive da discussão: como, pois, val proibir que so discuta? Todo interesse, toda instituiçio social se convertem apui um ideäls gerais, se ventilam sob a forma de idéas; como, pois, al gum interesse, alguma instituição văo sintar-se acina do pensamento e impor-se como atrigo de te? A luta dos oradores na tribuma provoca a luta dos escritores da imprensa, o clube de debates do parlamento se complementa mecessatramente com os clutes de debates dos saloes e dis tabernas, os representantes cuc apelam continuanente para a opi-

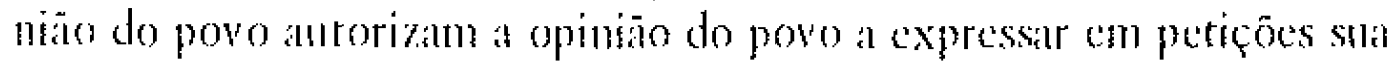
verdadeira opinião. () regime parlanchtar o deja todo para a decisāo

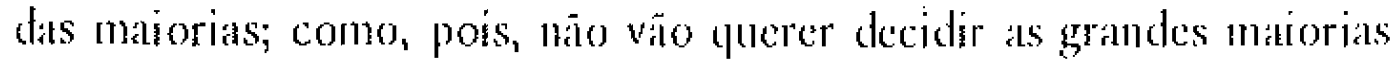
fora do parlamento?"?

A necessidade de un longo periodo previo de prática e aprendizagen deve ser muito sublinhada. Irata-se de que essas capacidades estão internalizadas no grosso da classe c que, por si mesma, se podem desprender en termos quase naturais ou espontâneos. Quer dizer, sem uma tensão extrema. Na ausência destas tradiçócs, nos momentos de crise revolucionária, o mundo do trabalho muitas vezes é capaz de desprender, de maneira quase milagrosa, essas capacidades. Porém, ao preço de una tensino extrema. Por isto mesmo, esse desenvolvimento dura ponco, os trabalhadores "se esgotam" e se retiram da coisa pública, delegando a outros a administração do poder.

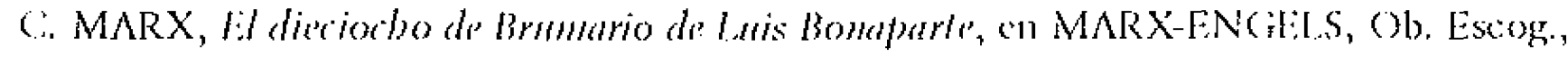
Tomo [, p. 446. Moscon, Fd. Progresso, 1973. 
Sem se agregarem ao contexto de uma sociedade capitalista, essas capacidades nunca poderão desenvolver-se e desprender-se à plenitude. Como bem se tem dito, é exercendo o poder que se aprende a exercê-lo. Este desenvolver as capacidades de direção do mundo do trabalho é justanente uma das tarefas centralíssimas do socialismo. Mas, assim como ninguém chega à álgebra sem ter passado antes pela aritmética, há aqui um mínimo prévio indispcnsável. Se este não existe e também deve ser adquirido durante o período socialista, antes de tê-lo adquirido, a classe trabalhadora haverá perdido o poder.

\section{CAPACIDNDE POLITICA DE CLASSE}

Esta capacidade deve ser medida a respeito de dois aspectos básicos.

Primeiro, capacidade para lograr uma plena e sólida unificação política da classe trabalhadora. Nas condiçóes contemporâneas, isto nāo é nada óbvio, pois o mundo do trabalho assalariado encontra-se cindido em múltiplas camadas e segmentos. Existem diferenças de ingresso, de valores e de estilos de vida, que chegam a semear a dúvida sobre a existência mesma de una classe em si. Não é possível entrar aqui em uma discussão desse ponto, mas, a "suposição de existência" é evidentemente uma condição sine qua non à idéia mesma do socialismo. Mas se a aceitamos, isto não mancha a heterogeneidade objetiva e subjetiva da classe e a, conseqüente, necessidade de encontrar c desenvolver um marco unificante.

Segundo, capacidade para implementar amplas e sólidas alianças classistas. Trata-se, aqui, de criar e fortalecer um vasto bloco popular; capaz de encabeçar e dirigir o processo de construção da nova ordem. Esta capacidade se mede comparando a magnitude da frente ou bloco popular efetivo, com o qual se desprenderia o que temos denominado "alinhamento potencial objetivo".

Por certo, um e outro aspecto estão intimamente associados à organização política da classe, a sua natureza e características. Também aqui, deparamos com um de seus problemas complexos e altamente debatidos. Não podendo entrar na discussão, basta-nos dizer: 
i) essa organização deve estar a serviço do trabalho e não o trabalho a serviço da organização. A organização pode e deve propor, mas é o trabalho - inclusive equivocando-se - que deve dispor. Não pode haver, aqui, imposiçóes. O que; permita-se acrescentar, não deve ser interpretado como uma alegação en tavor da pura espontaneidade adesista ou à acomodação irreflexiva e acrítica do órgão às posturas da classe. Em suma, a não imposição não é equivalente ao acordo irrestrito. O desacordo deve dissociar-se completamente da imposição; ii) essa organização, em alto grau, deve pré-figurar internamente o tipo de sociedade última a que se aspira.

\section{Ambiente Externo minimamente FAVORÁvel}

O ambiente internacional poderia chegar a ser tão desfavorável a ponto de provocar um colapso rápido do projeto socialista. No outro extremo, poderia ser favorável o suficiente para suavizar boa parte dos obstáculos ao desenvolvimento do projeto. Para nossos propósitos pode nos bastar um mínimo do mínimo. Quer dizer, um contexto internacional que não chegue a colapsar ou a deformar o curso do projeto.

O contexto internacional deveria permitir: i) o acesso a um mercado externo suficientemente amplo, para tornar desnecessário que o país entre em um processo náo buscado de 'autarquização' da economia, com toda a ineficiência que isto acarreta; ii) o acesso aos últimos avanços e inovaçōes da ciência e da tecnologia; iii) evitar que surjam bloqueios econômicos e militares. Muito especialmente, tratase de evitar a necessidade de manter um excessivo gasto improdutivo, como os gastos de defesa militar. Em muitos casos, como bem se sabe, os recursos que se comprometem para evitar eventuais agressões militares, terminam por prejudicar, irremediavelmente, o curso socialista do processo.

O contexto internacional favorável não necessariamente implica na presença de um campo socialista forte. Ainda que, claro está, se este existisse, as coisas seriam menos complicadas. Em um contexto capitalista, sob certas condiçōes, o requisito também poderia ser alcançado. 
$\mathrm{Na}$ atualidade, este requisito de un contexto internacional minimamente favorável, a muitos poderá parecer incansável. Por isto mesmo, o avanço ao socialismo resultaria impossível. Mas não existo tal.

Hoje, a revolução $\mathrm{cm}$ tal ou qual país pode não estar na ordem do dia. Mas amanhá, quando estiver, cabe esperar com muita segurança que a sitwaça internacional scja diferente.

l'ara tanto: i) poderiam dar-se alguns processos paralelos, cm dois on mais paises; ii) em outros paises, pode-se esperar a existência de un movinento popular, não tão forte como para desencadear um processo de mudança maior, mas sim, com força suficiente para impedir ou atenuar a eventual politica agressiva de seu próprio governo contra os novos regimes socialistas; iii) também abe esperar a presença de um nomento internacional mais conMitivo. (Quer dizer, que surja a possibilidade de aproveitar os conflitos interimperialistas em favor dos novos regimes. Os três pontos recém assinalados - deve-se sublinhá- lo - vão são uma expressão de bons desejos. São algo que se pode c deve esperar de um período revolucionário. Dito de outro modo: esse tipo de contexto internacional joga não somente como um importante fator permissivo. Funciona, também, como um fator impulsor. () ponto pode visualizar-se taubém desde um ângulo inverso: o processo de desenvolvimento de uma situaçáo revolucionária nacional provocando, por sua ve\%, a alteração de uma correlação internacional de forças. E o faz cm favor desses processos revolucionários.

Por certo, se a ruptura socialista tem lugar cm um país capitalista altamente desenvolvido a de grande tamanho (que era a situaça visualizada por Marx), a dependencia do ambiente externo será bastante menor. $\Lambda$ ssim mesmo, muito forte será o impacto na correlação internacional de forças. Algo que, obviamente, facilitaria cuormemente o destino de futuras irrupçóes socialistas em paises de menor tamanho e não tão desenvolvidos. 
5. UMA ADVERTEENCIA NECTESSÁRIA

A presença das condiçóes anteriores não assegura que o curso da estratégia discutida seja exitoso. Mas sim, eleva consideravelnente as probabilidades desse êxito. De modo análogo, sua ausência ou presença débil näo assegura o fracasso do projeto. Mas sim, eleva suas probabilidades.

Para o caso, não deveríamos olvidar o que a experiência histórica tem mostrado com singular eloqüência: em linhas gerais, a revoluça de talhe socialista tem brotado em países bastante atrasados e, por isto, premissas cono as antes moncionadas têm tido una presenca muito débil. Por certo, esse mesmo atraso explica a alta vulnerabilidade do capitalismo. Mas, por sua vez, tem tornado mais que difíceis as tarefas de construçio de uma nova ordem ${ }^{8}$.

\section{As TAREFAS POLIITICAS}

\section{CONSIDFRAÇOEFS I'RÉVIAS}

O Lstado, se houver concordancia, é uma instituição social que satisfaz determinadas funçóes. Na atualidade, poderia-se falar de uma instituição polifuncional, mas aqui nos interessa somente que é a mais especifica e essencial, a que lhe outorga sua razão de ser última e que, por isto mesmo, explica sua origem. Lm poucas palavras, trata-se de preservar as bases ou fundamentos (isto é, as relaçóes de propriedade) do sistema econômico vigente. No dizer de Engels, trata-se de

"una organizaçĩo da correspondente classe exploradora para manter as condiçốes exteriores de prodıção e, portanto, particularmente para manter pela força a classe trabalhadora nas condiçōes de opressão (a escravidão, a servidão c o trabalho assalariado), determinadas pelo modo de produção existente".

"Quanto mais atrasado é un país que, em virtude dos zigne-zagues da história, tem tido que coneçar a revolução socialista, mas dificil resulta passar das velhas relaçôcs capitalistas às relações socialistas. Aqui, às tarefas destrutivas se sobrepóem outras novas: as tarefas de organização". Ct. V. I. LLNIN, O. C, T. 27, Moscon, 1965.

9 F. ENGELS, Ami-Indring, pp. 227-8. Eđl. Cartago, Buenos Aires, 1973. 
Esta função de salvaguarda é cumprida por meio do uso (explícito ou em potencial) da força, quase sempre lcgalmente sancionada. Para isto dispõe de grupos especializados e separados de homens (as forças armadas, em especial), os quais estão organizados de man eira peculiar e concorde con as funçôes a satisfazer. Aqui, a clave orgânica reside no patrão de organização burocrática. Como disse Moore,

"uma burocracia (...) é uma hierarquia de funcionários remunerados na qual cada componente do grupo é controlado unicamente por seus funcionários superiores e na qual o trabalho do grupo estíl dividido e centralizado como em uma fábrica"' ${ }^{\prime \prime}$.

\section{Moore acrescenta que}

"1als burocracias dos Estados capitalistas, os funcionários stperiores, civis e militares, provêm en geral das classes capitalista e latifundiária. Nos graus intermediários dá burocracia civil, muitos funcionários são de origem pequeno burguesa. Os gralus inferiores da polícia e das forças armadas sî́o cobertos en parte com o campesinato e o proletariado. Segne-se, sem cmbargo, da caracterização básica da organização burocrática, que a conduta de todo o grupo está determinada náo pelas decisóes da mai oria de setis membros, mas pchis decisốes dos fumcionários superiores, militares e civis"1!

É interessante sublinhar a correspondência nada menor que se estabelece entre este tipo de organizaça social e a que caracteriza a fábrica capitalista. Nestas entidades, a atividade desenvolvida está submetida a um planejamento bastante estrito. Mas este planejancnto, ao ser a expressão de uma vontade - a do capitalista - que é estranha ao operário coletivo, é inposto aos trabalhadores. Quer dizer, o canal de mando tlu de cima para baixo, igual ao que se faz nas entidades burocráticas de talhe estatal. Segundo Marx,

10 STANLEY MOORE, Critica de la democracia capitalisha, p. 94. Ed. Sigio XXI, Buenos Nires, 1974.

11 Ibid., p. 95. 
"desde um ponto de vista ideal, a coordenação de seus trabalhos se apresenta aos operários como planejamento; praticanente, como a antoridade do capitalista, como o poder de uma vontade estranla que subnete sua atividade aos fins perscguidos por apuela". Por isto mesmo, "a direção capitalistá é uma direção despótica" 12.

Posto o anterior, podem-se entender melhor o porquê das reivindicaçôes socialistas básicas, tanto no espaço da economia (en nível de relaçóes de produção, en especial) como no da política. Em suma, trata-se de que "os de baixo" sejam os que tomam as decisóes. Quer dizer, que assuman o poder tanto dos assuntos políticos, como dos econônicos.

Antes de passar a expor as propostas socialistas mais concretas, convém acrescentar um ponto de especial interesse. Ao falar da organizaça burocrática inerente ao Estado burgues, temos sublinhado que os canais de mando flucm de cima para baixo. Por isto mesmo, sc os postos burocráticos mais altos (por exemplo, o Presidente da nação) se preenchem com recurso ao método do sufrágio universal, pode parecer que o povo poderia determinar que o aparato estatal funcione a seu favor. Quer dizer, que passe a representar seus interesses. Em termos formais, assin é forçoso reconhecer o mesmo ordenamento constitucional e legal. Sen embargo, do dito ao feito ocorre abrir-se um abismo insondável. $\Lambda$ pontemos as razōes básicas:

a) Por suas mesmas extenuantes o opressivas condiçōes de trabalho, quando o operário sai da fábrica não está como para dedicarse à política è cultura, só deseja descansar e esquecer. Por isto mesno, mal poderia erigir c desenvolver um projeto alternativo crítico ao poder que responda aos seus interesses. E, se algumas horas de ocio se pode procurar, nelas ocorre ser atrapalhado por toda a alienante parafernália da indústria capitalista do ócio. Os padres e, em especial, os massmedia cono a telcvisão e o cinema, se encarregam de idiotiza-lo e de transforma-lo em um dorminhoco ou boneco intelectual, ao estilo dos caribenhos made in Miami. Em breve, quando o sistema opera em condiçoes 'normais', se assegura que o povo vote a 
favor dos interesses do capital;

b) também é certo que as condiçóes objetivas da exploração e dominação provocam a rebeldia e luta dos trabalhadores. En algumas ocasióes, em certos momentos ou períodos, esta luta se estende e aprofunda. Neste contexto de luta, a consciência operária se desenvolve e se pode desprender, em maior ou menor grau, da ideologia burguesa dominante. Quer dizer, tende a romper com a alienação imposta pelos "aparelhos ideológicos do Estado" e os trabalhadores tendem a acercar-se ou encontrar-se com a verdade de sua situaçấo e de seus interessés objetivos. Se este processo avança o suficiente, o mundo do trabalho pode inclusive chegar a triunfar nas contendas eleitorais. Seus representantes assumem o governo (suposição que nem sempre se cumpre) e, portanto, pode-se supor que façam trabalhar a burocracia estatal em favor dos interesses populares. Mas não existe tal: i) em algumas ocasiôes, esses representantes são comprados pelo capital e terminam "adorando o que antes haviam queimado"; ii) en outras, se esses representantes resistem ao assédio do capital, deparan-se com um aparato estatal burocrático que os corroe e bloqueia. No limite - caso da burocracia armada - sem rodeios, se rebela e dá um golpe de Estado nesses ingênuos impertinentes, que haviam acreditado no mito dos governos como expressāo da vontade majoritária da nação ${ }^{13}$. Como bem se tem dito, no seio do sistema capitalista, quan to mais se aprofunda no conteúdo democrático do sistema, mais próximo se está da quebra instinucional (isto é, do golpe de Estado). Ademais, como quanto maior o conteúdo democrático, também é maior o desenvolvimento ideológico e político dos trabalhadores (um aspecto incentivando o outro e vice-versa), também podemos concluir que a democracia burguesa funciona tanto melhor é é tanto mais estável, quanto mais débil seja o movimento popular. E, ao contrário, quanto mais forte e autônomo seja o movimento popular, mais próximo se estará do despedaçamento da democracia. Para os ex-mar-

13 "En 10 de março (de 1850 ), o sufrágio universal se pronunciou dirctanente contra a dominação da burguesia; a burguesia contestou proscrcvendo o sulfágio universal". Conf. C. MARX, O Dezoito Brumario de Luis Bomaparte, em MARX-ENGELS, Obras Escollhidas, Tomo I, p. 450. Moscon, Ed. Progreso, 1973. 
xistas que agora celebram com plumagens de cores neo-liberais, a lição a extrair é original: o movimento do trabalho deve moderar e limitar suas reiviṇdicações. Resumidamente, para salvaguardar a democracia, deve aceitar a exploração e dominação do capital. Os outros, os que rechaçam viver com a cabeça entre as pernas, extraem uma muito distinta conclusão: defende-se a democracia aprofundandoa e, para isto, o povo deve organizar seu poder de coação e, chegado o momento, saber aplicá-lo contra o poder coativo manejado pelo grande capital.

Para nossos propósitos, o ponto a sublinhar-se seria o da íntima associação que se estabelece entre desenvolvimento democrático e desenvolvimento do movimento popular. Sobre isto voltaremos.

\section{O PROBI.EMA MAIS GERAL: CRIAR UM PODER POPULAR E DEMOCRÁTICO}

Trata-se do problema mais geral e vital, pois atende à mesna natureza socialista do projeto. Falamos da forma ou modo de organizar a vontade e o poder dos trabalhadores. Quer dizer, que formas de organização social devem desenvolver-se para (i) recolher e (ii) sintetizar a vontade dos trabalhadores? Como assegurar que essa vontade, além de bem recolhida, se traduzirá em decisôes efetivas e congruentes com essa vontade? Quer dizer, como se pode assegurar e reproduzir um poder democrático que efetivamente esteja em mãos da coletividade dos trabalhadores?

As perguntas recém-mencionadas são vitais. De fato, poderia-se sustentar que nelas e em suas respostas se encerra a possibilidade mesma de construir uma sociedade socialista. E que os fracassos conhecidos, em grande medida, têm a ver com a incapacidade para dar-lhes, na práxis sócio-política concreta, as respostas adequadas.

A organização de um poder democrático e popular é um desafio que opera, no mínimo, em dois níveis.

Primeiro, no espaço da política em termos de organização estatal. Trata-se de que, efetivamente, o Estado seja um Estado de novo tipo, que de verdade responda aos interesses do mundo do trabalho. Segundo, em nível de relaçôes de propriedade. O qual, por sua vez, 
se constitui em dois subniveis: i) em termos de fábricas ou empresas. Nelas, o coletivo de trabalhadores deve exercer o poder patrimonial (isto é, a propriedade), decidindo que uso dar à forças produtivas e rompendo com os padróes de divisão do trabalho herdados do capitalismo; ii) em termos de conjunto de empresas que respondem à vontade decisória dos trabalhadores. Quer dizer, em termos de setor socialista da economia. Este ponto é anda mais decisivo que o anterior pois representa o avanço até um estágio superior da propriedade dos trabalhadores. Se resume na gestão unificada e coletiva do conjunto da economia, sujeita ao controle e propriedade dos trabalhadores. Por isto mesmo, supóe a unificação social e política dos trabalhadores e deve traduzir-se en un plano de gestão da economia, plano que deve sintetizar a autêntica e democrática vontade do traballo.

Trata-se, em suma, de que o mundo do trabalho comece a assumir-se como dono de si mesmo e de seu destino, que desenvolva as condiçóes para sua autodeterminação e plena liberdade. Algo que, necessariancnte, será um processo muto complexo, nuito amplo e muito sinuoso. E que supōe, em seu simples ponto de partida, a presença de condiçōes materiais e culturais que, em termos gerais, ocorrem estar muito pouco desenvolvidas ou, sem rodeios, ausentes nos países capitalistas menos avançados. L valha o sublinhado: se cssas premissas ou pré-requisitos não se cumprem, dificilncute poderá frutificar e consolidar-se um projeto de natureza socialista.

\section{O problema do Estado}

Primeiro, trata-se de dissolver o aparato estatal vigente e herdado. Isualmente, quando se cstabelece esta exigência, pensa-se nos aparatos coercitivos e "na direção donde apontam as baionetas".

Não obstante, o problema mais decisivo é outro e se refere ao tipo de estruturação que tipifica o velho Estado. Essa organização não serve - é disfuncional - para um ordenamento social de molde socialista. Em breve, não se pode verter o novo vinho em velhos odres. Por isto, a dissoluçáo é chave.

Em segundo, está o problema de substituir o velho. Em poucas palavras, trata-se de gerar uma nova estrutura ou forma de organiza- 
ção social. Ou, como se queira, um novo sistema de status e regras. $\Lambda$ chave está em que os canais de nuando fluam desde baixo até em cima e, portanto, assegurar que o novo aparato funcione em favor da vontade dos "de baixo". Contudo, deve assinalar-se que sempre existe o perigo de reproduzir inconscientemente o velho sistema, pelo menos em alguns de seus elententos. Para o caso, medidas como revogabilidade dos representantes, a supressão de privilćgios burocráticos, a rotatividade e particjpação obrigatória em trabalhos de produção, resultam antídotos imprescindíveis.

\section{A ORGANIZAÇ̃O DA SOCILDADE CIVIL E O PROCESSO DI: DESESTATIZAÇÃO}

Todas as sociedades devem satisfazer certas funçóes de caráter geral. Estas, são conseqüências do caráter comunitário da convivência humana e, quanto mais complexas, se tronam as sociedades, mais crescen e se ampliam essas tarefas de coordenação. Nas sociedades de classes, o grosso dessas tunçóes - se não é que todas - são apropriadas pelo Estado. Quer dizer, passam a ser desempenhadas, de uma maneira que parece "natural", pelo aparato estatal. Além de tudo, em nível de ideologia dominante, entende-se o Estado como representante e órgão de execução da "vontade geral". Na prática, essa apropriação funciona como uma expropriação da sociedade civil e dá lugar a certos efeitos que convém mencionar: i) o cumprimento dessas funçóes assume un claro sentido de classe. Quer dizer, o que aparece como "vontade geral" não é, senão, o disfarce com que se encobre a vontade particular da classe dominante. Dito de outra maneira: o Estado se encarrega de satisfazer essas necessidades gerais, mas ao fazê1o, o faz beneficiando a classe doninante; ii) para cumprir essas funçóes, o Estado concede a si mesmo pessoal especializado, ao qual organiza conforme a norma orgânica, que é a própria do aparato estatal: a norma burocrática. Por isto mesmo, as diretrizes e sua execução assumem um conteúdo antidemocrático.

Em un contexto socialista, essa expropriação deve começar a ser desmantelada. Quer dizer, trata-se agora de expropriar ao Estado e devolver à sociedade civil a execução dessas funçôes de caráter geral. Com isto, será a prática social massiva mesmo que irá desvelando a 
grande farsa do Estado político como representante da vontade geral e, por sua vez, mostrando-o tal como é em scu núcleo mais essencial, como un aparato de repressão que será tanto mais supérfluo quanto menos necessária seja essa repressão (necessidade que será tanto menor quanto seja maior o avanço do sistema socialista). Trata-se, em suma, de dissociar a idéia de vontade geral da idéia de Estado e mostrar as reais condições para que possa emergir a vontade geral, náo conno máscara, mas como expressão de uma autêntica conunidade de interesses ${ }^{14}$.

Para cumprir com o anterior, devem desenvolver-se a fundo as sociedades civis não estatais (ONG's). Se isto ocorre, o Fstado irá emagreccndo mais e mais (não esqueça-se que a meta última do socialismo é a supressão de todo Estado, incluindo o de novo tipo) e, por sula vez, a sociedade irá se resgatando e fazendo-se dona de si mesma. As ONG's devem ir entendendo-se mais e mais. Abarcando mais e mais funções de caráter geral. Todas clas, salvo as de repressão, que são as específicas do Estado.

Por certo, um processo como o insinuado não pode ser, senão, muito amplo. Ainda assim, ziguezagueante e conflitivo. Durante um largo período o conjunto da sociedade civil estará integrado por grupos sociais heterogeneos, que respondem a diferentes interesses objetivos. Para esse todo, a comunidade continuará sendo ilusória. Por isto mesmo, a democracia per-si e a coação que the é própria, seguiráo vigentes ${ }^{15}$. Mas, enquanto o processo vai se desenvolvendo, a democracia se aprofundará mais e mais. Tanto, que terminará por desaparecer ${ }^{16}$. Quer dizer, a maioria não imporá sua vontade à minoria, mas a convencerá. Nesse interim, a maioria e sua vontade genérica deve auxiliar-se da força do Estado, para impor e fazer respeitar suas decisóes.

\footnotetext{
14 A emergêtncia dessa commidade, por certo, supõe a destruição das relaçócs de exploração de classes. Se estas relações existem, a contunidade não ć mais que una pura ilasão.

15 A democracia, entendida aqui como forma estatil em gte a maioria domina e impö, coativanente, sua vontade à minoria.
}

16 Quer dizer, subsiste a vontade da maioria e desaparece a coaçĩo. 
Como venos, duas são as diretrizes básicas para o período. Um, desenvolver e consolidar um Estado de novo tipo, que substitua sem condescendência ao velho aparato, inútil para os novos propósitos. Dois, desenvolver a capacidade de autogestāo da sociedade civil. Muito em especial, a dos trabalhadores, que são seu componente majoritário. Um e dois se podem ser sintetizados em um só propósito: desenvolver a vida democrática, em extensão e profundidade, até suas últimas consequiências.

\section{AS TAREFAS ECONÓMICAS}

\section{TARETAS IJF ORDI:M QIJALITATIVA}

Se nos concentramos no básico, se referem à transformação buscada nas relaçōes de propriedade. Do mesmo modo, às regras do mercado e do planejamento.

O modelo deve afetar as grandes corporaçóes oligopólicas, sejam estrangeiras ou nacionais. Muito especialmente, em termos de setores financeiro (aqui, em cen por cento) e industrial. Estas empresas controlam o grosso do excedente econômico gerado pelo país e jogam um papel decisivo no curso da economia. Como regra, seus interesses resultan de todo alheios a uma estratégia de molde socialista e, por isto, devem ser afetados.

$O$ controle dos meios de comunicação resulta igualmente vital. O novo regime deve ser especialmente estrito e cuidadoso a respeito.

En princípio, o setor econômico socialista deve integrar-se com estas empresas. Poderá, sem embargo, surgir alguma situação que dificultará a constituição de um autêntico setor socialista. Isto, no caso de uma capacidade de gestão inadequada por parte dos trabalhadores. Neste caso, a via mais eficaz seria a combinação da velha propriedade con um novo capital aportado pelo Estado. Deste modo, junto ao socialista, se constituiria un segmento de capitalismo de Estado ou 'misto'. A idéia é aproveitar as capacidades gerenciais ali existentes, assegurar a supervisão estatal c estimular o desenvolvimento, a médio ou longo prazo, da capacidade diretriz dos trabalhadores. 
Certamente, no setor socialista devem cumprir-se os critérios antes mencionados. Assim, devem ser autenticamente satisfeitos os interesses do trabalho, desenvolver novas formas de divisão do trabalho e de gestão, novos tipos de tecnologia e novos modos de relacionamento com a esfera do consumo. Por isto mesmo, deve funcionar como um setor líder, tanto pelo atrativo de sua forma de gestáo, como por sua superioridade dinâmica e produtiva.

Existe um segundo aspecto sobre o qual convém ensiar uma mínima referencia. Trata-se do peso do mercado no funcionamento da nova economia.

Até há algum tempo, muitos identificavam o socialismo com um regime de planificação central plena. Hoje, não poucos autores falam de un "socialismo de mercado" e atribuem ao mercado virtudes que jamais teve, nem poderá ter. O ponto, na realidade, deve ser abordado por outro lado. Deixar nas mãos do mercado a atribuição dos recursos, em nada condiz com as metas socialistas últimas. Estas, exigem uma gestão unificada (isto é, planejada) c consciente dos processos economicos e, por isto mesmo, suprimir de todo o mercado. Mas esta supressão é um problena que responde a condiçôes objetivas e não a decisôes voluntaristas ou legais. Enquanto as forças produtivas não operarem com o grau de socialização suficientc e os trabalhadores não tiverem desenvolvido adequadamente sua capacidade de gestão, o manejo planificado da economia náo poderá substituir o mercado ca lej do valor. (O intento só redundará - como o demonstra a experiência histórica conhecida - em uma centralizaçâo burocrática forçada, politicamente perigosa e cconomicamente ineficaz.

Para a fase ou período que nos preocupa, portanto, o mercado continuará jogando um papel vital. A gestão planejada se aplicará somente ao setor socialista e em termos incompletos. Isto, pela articulação do segmento socialista com o resto da economia e porque, muito provavelmente, seu entrelaçamento interno não estará suficientemente avançado.

Trata-se, em todo caso, de um mercado regulado pela autoridade estatal. Por meio do uso dos correspondentes instrumentos de política, deve-se buscar uma atribuição de recursos coerentes com as me- 
tas estratégicas. A inversão, a distribuição do ingresso e os nexos com o resto do mundo, são três áreas de especial atenção e que exigem uma eficaz e forte regulação. No período, a política econônica passa a jogar um papel central, deve ser muito ativa e, na medida do possivel, não discricionária ${ }^{17}$.

\section{TAREFAS DE ORDLM QUANTITATIVA: CRESCIMENTO E DISTRIBUICÃO DE RENDA}

Primeiro, necessita-se avançar rapidamente até uma situação de pleno emprego e, assim mesmo, elevar substancialmente os níveis de vida da população trabalhadora. É muito possível, que isto implique que os salários aumentem sua participação na renda nacional e que, consecutivamente, os setores que produzem bens de consumo, elevem sua participaça no produto nacional. Com isto, o "potencial de reprodução ampliada do sistema" ${ }^{8}$ deve diminuir.

Segundo, as exigências de ocupação plena e de um crescimento mais dinamico, obrigan a ampliar drasticamente o esforço de inversão. Quer dizer, o quociente acumulação a produto agregado deve se clevar de modo considerável. Muito provavelmente, se supomos um crescimento do PIB da orden de 6 a $7 \%$ anual e um quociente produto a capital fixo da ordem de 4 a $5 \%$, deveria-se chegar a un quociente de inversão que giraria em torno de uns $2.5 \%$ ou algo mais da renda nacional. Por certo, o setor socialista só poderá cobrir uma parte do esforço de inversão e, para isto, ao setor privado capitalista the deve assegurar adequadas condiçóes de rentabilidade e certeza.

A primeira vista, elevar a taxa de acumulação e, por sua ve\%, elevar a participação salarial (com a conseqüiente caída do potencial de reprodução ampliada do sistema) podem parecer metas incompatíveis. Não obstante, o novo sistema deve contabilizar dois mecanismos de

${ }^{7}$ A análise da política conônica não ć tema deste ensaio. Ademais, por sulas próprias características, essa análise deveria cfetuar-se em termos mais concretos, referidos a um país chado.

is Ao quociente entre o produto excedente e o produto agregado total do sistema denominamos potencial de repridução ampliada. O produto excedente, por sua vez, é ighal à diferenca entre o produto agregado e o produto necessário. Este último, é igual à parte do produto apropriada pelos trabalhatores produtivos. 
ajuste en torno deste problema.

O primeiro e vital, é a forte redução do peso dos gastos improdutivos (burocracia estatal, gastos militares, gastos relativos à circulaça, etc.). O decréscimo deve ser tal que, ainda que diminuído o potencial de reprodução ampliada, logre-se elevar drasticamente a taxa de acumulação. Quer dizer, o aumento da participação salarial deveria ser compensado - pelo menos em grau considerável - pelo decréscimo do peso relativo dos gastos improdutivos.

O segundo tator a considerar se refere à dinâmica da produtividade do trabalho, nos ramos que produzem bens de consumo (agricultura, têxtcis e vestuário, eletrodomésticos, etc.). Se a produtividado sobe suficientenente rápido, a pressão, ao contrário do potencial de reprodução do sistema, poderá se debilitar. Quer dizer, a expansāo programada dos salários não necessariamente se situará acina do crescimento da produtividade. Inclusive, e este seria o caso ideal, poderiam crescer algo menos, suavizando-se, assim, as pressões peló uso do excedente. Mas, advirta-se: isto nāo se deve alcançar por via de um menor crescimento dos salários, senão que por via de uma maior expansão da produrividade.

A reprodução muito rápida da produtividade não é algo simples.

Se no país existe um forte sctor de economia camponesa, atingir os elevados ritmos que o sistema exige pode ser impossível. Este tipo de regime econômico não é capaz de aquiescer, nem de funcionar com elevados niveis de produtividade. E, se se pretende dissolvê-lo, o projeto socialista compra para si problemas políticos maiores (se rompe com a eventual aliança operário-camponesa) e não obtém nenhuma contrapartida en termos de uma agricultura moderna e sofisticada. Neste aspecto, a dura experiência soviética resulta contundente.

Por outro lado, as novas relaçóes de produção, de caráter socialista, deverian traduzir-se em niveis de produtividade mais e mais elevados. Quer dizer, a liberdade no trabalho e o controle desses processos pelos próprios trabalhadores, deveriam redundar em ritmos de expansāo da produtividade ainda mais elevados que os conhecidos pelo capitalismo. Ademais, e isto deve ser sublinhado, o estilo da expansão deveria ser diferente. No padrão socialista, não existindo os 
prejuizos contrários ao trabalhador, a maior produtividade não necessariamente deveria estar associada à maior densidade do capital mas, melhor que isto, a um uso mais eficiente dos recursos, algo que deveria possibilitar o trabalho livre. Por isto mesmo, poderia-se esperar uma relação produto por capital um tanto mais elevado nos setores socialistas de ponta ${ }^{19}$. E claro está que se isto se cumpre, suavizam-se também as pressōes por um esforço de acunulação maior ${ }^{20}$.

No nível médio de produtividade também influi o tipo de inserção internacional da economia.

En termos muito grosseiros, pode-se postular uma relação inversa entre o tamanbo da economia e seu grau de abertura cxterna. Se esta se reduz em excesso, a excessiva diversificação do PIB poderia provocar una dotaçáo ineficiente dos recursos e afetar a produtividade. Por outro lado, uma inserção orientada por vantagens comparativas estáticas seria ainda mais prejudicial. (O país, por pequeno que seja, deve alcançar certo desenvolvimento na esfera da produção de bens de capital. Isto, pela associação que existe entre cste setor e o desenvolvimento das capacidades científicas e tecnológicas e pclos efcitos de alavancagem e de irradiação aqui implicados.

$\Lambda$ especialização é benćfica se se estabelece em termos adequados. Para isto, deve buscar-se uma integração vertical, que seguindo a rota dos encadeamentos produtivos, traga consigo desde certo tipo de produtos finais, até certo tipo de bens intermediários e de capital. Lm poucas palavras, o justo rechaço a uma especializaçāo primárioexportadora não deve dar lugar nem à tentação autárquica, nom à utopia de gerar uma indiscriminada capacidade exportadora industrial. $\Lambda$ seletividade, em termos de opçóes com capacidade de alavancagem, é indubitável.

\footnotetext{
19 A relação produto por capital, definicionalmente, é igual ao quociente cutré a produtiviclade do trabaho e a densidade do capital. Fsta, é igual ao quociente entre capital fixoe ocupação. Nas novas condiçöes, supöe-se que a produtividade pode subir mais rápido quac a clensidade do capital.

20 Pode-se igualar a taxa de crescimento no resultado da multiplicação do quociente de inversão pela relaçâo produto por capital. Porén, sc esta se eleva, podc-sc conseguit o mesmo ritmo de crescimento com um menor esforço de inversio.
} 
Quan to à redução do peso relativo dos gastos produtivos, o assunto tampouco parece muito simples. Pense-se, por exemplo, no delicado problcma dos gastos militares em uma provável situação de cerco capitalista. Como a discussão do problema nos levaria demasiado longe, basta-nos sinalizar com o que aqui devemos lançar como um puro postulado: se essa redução nāo é possível, tampouco será possível o socialismo.

O problema da produtividade está relacionado com o do emprego. Para uma taxa dada de crescimento do PIB, se sobe o crescimento da produtividade, o emprego crescerá menos. Se o PIB cresce a $7 \%$ ao ano e a produtividade entre 4 e $5 \%$ anuais, a ocupação se elevará em $2-2,5 \%$ anuais. Para o longo prazo, pensando em países como $\Lambda$ rgentina on México, este ritmo poderá ser suficiente. Em um prazo mais imediato, pela necessidade de absorver a força de trabalho desocupada (aberta ou disfarçadamente), esse incremento seria insuficiente. Se supomos que as metas globais médias de acumulação, crescimento do PIB e de produtividade nāo são modificáveis, seria necessário ensaiar uma estratégia al hoc. Por exemplo, definir um setor conômico cuja função básica seria a de absorção da força de trabalho. Para isto, é preciso punir, aí, a incorporação de tecnologias liberadoras de mão-de-obra. Assim mesmo, um adequado estorço educativo (em si mesmo imprescindivel) deveria permitir retardar a incorporaçáo de certos segmentos demográficos ao mercado da força de trabalho e suavizar o problema. (O ponto implica una dualização inicial da economia, pois junto ao setor descrito deve operar outro em que as exigências devem ir pelo lado da produtividade e não pelo do emprego. Por certo, este último setor deve abarcar todos os ramos (e empresas) que, direta ou indiretamente, participam do comércio externo.

\section{FORÇAS SOCIAIS EM JOGO E ACUMULAÇÃO DE FORÇAS}

1. As Forchs Socials em Jogo di o Alinilamento Possivei.

Recordemos que a estratégia aponta para o que temos qualificado como socialismo embrionário. Neste contexto, pelo teor das tare- 
fas básicas que se levantan, a grande burguesia monopólica, nacional e estrangeira, aparece definida como força oposta principal. Para as forças impulsoras da mudança, o problcma reside em restar- the o máximo possivel de forças sociais de apoio junto a esses setores.

Quanto ao resto da classe burguesa - a não monopólica -, parece muito difícil pensar que seja possível sua integração ao bloco popular. Por isto, com respeito a esses grupos sociais, a meta máxima a perseguir deve ser sua neutralização política. Para o caso da burguesia agrária, isto resulta especialmente importante.

Todas as demais classes a segmentos sociais passam a formar parte do que temos denominado "alinhamento potencial objetivo" favorável à nova orden. Neste contexto, resultan claras as duas tarefas básicas que emergem nesta esfera: i) unificar os trabalhadores; ii) formar e desenvolver uma vasta aliança classista, aproximando todo o possivel bloco ou frente efetivos do "alinhanento potencial objetivo".

\section{A ACUMULAÇÃO DE FORC,AS}

Como ja se tem sinalizado, trata-se de desenvolver a capacidade de luta e de direção dos trabalhadores, em particular, co do povo cm geral ${ }^{21}$. Supostamente, o processo implica forjar a organização da classe trabalhadora e sua capacidade de luta cm todas as frentes. Assim mesmo, avançar a uma correlação de forças que corresponda cada ve\% mais com a que poderia determinar o "almhamento potencial objetivo". Mas a pergunta ć, como satisfazer estes propósitos?

Linitando-nos ao mais essencial, a resposta năo representa um mistério maior: trata-se, no básico, de impulsionar as formas democráticas substantivas em todos os âmbitos da vida social. Da cultura, da política e da economia. Quer dizer, de criar e impulsionar as organizaçôes civis não cstatais cm todos csses âmbitos. Desencadcandose esta dinâmica, o trabalho não só se fortalece, mas leva a luta a um espaço no qual a burguesia não pode competir e, por isto mesmo, ter-

21 Por "povo", neste contexto, deve entender-se o conjunto de segmentos e de classes sociais gue conformam o bloco impulsor potenciat. Quer dizer, os grupos que integram o "alinhamento potencial objetivo" em favor da mudança. 
mina por mostrar-se em toda a sua nudez antidemocrática. $\Lambda$ este respeito, Rosa Luxemburgo era diáfana:

"se a democracia se tem convertido para a burgnesia cm algo, em parte supérfluo, em parte enfadonho, para a classe operária resulta necessária c indispensável. É necessíria, un primciro lugar, porçute cria as formas políticas (autoadministração, sufrágio, etc), que scrvirẫo ao proletariado de impulso e apoio en sua transtormação da sociedade burgucsa. Mas resulta indispensável também, cm segundo ligar, porque só nelá, ha luta pela democracia, no exercício de sens dircitos, pode chegar o proletariado a tomar consciência de seus interesses de classe e de sias tarefas históricas"

Segundo vemos, a eventual ausência ou debilidade das premissas năo implica funcionar como lanterninha nen cruzar de braços c esperar passivamente - um pouco ao estilo do plejánov mais velhoque a história avance e forje essas precondiçoes. Também estas, no mais alto grau, passam a ser responsabilidade do trabalho. E, segundo se tem dito, ao acumular forças para essa luta, de fato, o trabalho começa a aprender o modo mesmo de construir o socialismo. 